\title{
Possible Changes in Maternal Plasma Cortisol, Adrenocorticotropic Hormones, Pregnancy Associated Plasma Protein-A and Alpha-fetoprotein in HIV Pregnant Women at NAUTH Nnewi, Nigeria
}

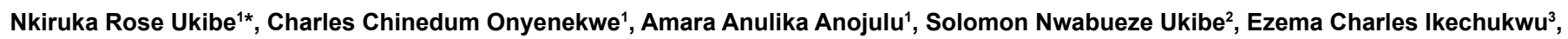
Friday Alphred Ehiaghe ${ }^{4}$, Paul Isaac Emeje ${ }^{5}$ and Uchechukwu Anthonia Ezugwu ${ }^{3}$

${ }^{1}$ Deparment of Medical Laboratory Science, College of Health Sciences, Nnamdi Azikiwe University, Nnewi Campus, Nnewi, Anambra State, Nigeria ${ }^{2}$ Prosthesis and Orthotics, School of Health Technology, Federal University of Technology Owerri, Nigeria

${ }^{3}$ Deparment of Medical Rehabilitation, Faculty of Health Sciences and Technology, University of Nigeria, Enugu Campus, Enugu State, Nigeria

${ }^{4}$ Department of Hematology, Igbenedion University Okada, Benin City, Edo State, Nigeria

${ }^{5}$ Department of Chemical Pathology, Federal Medical centre, Lokoja, Kogi State, Nigeria

\begin{abstract}
Background: There is limited information on if HIV infection induces stress in pregnancy. HIV can possibly contribute to the alterations in some fetal viability hormones thereby lead to adverse pregnancy outcome. The present study aimed to assess the possible changes in maternal cortisol, Adrenocorticotropic (ACTH), Pregnancy associated plasma protein-A (PAPP-A) and alpha-fetoprotein (AFP) hormone concentrations in HIV-infected pregnant women and their pregnancy outcomes.
\end{abstract}

Methods: A cross sectional study of 80 (Eighty) volunteer pregnant women aged (18-49) years recruited during routine antenatal clinics in Nnamdi Azikiwe Teaching Hospital, Nnewi, Anambra State, Nigeria was conducted. The participants were divided into groups: 40 (forty) apparently healthy pregnant and 40 (forty) HIV-infected pregnant women. $5 \mathrm{ml}$ of morning blood samples were collected from each subject in their $1^{\text {st }}$ and $2^{\text {nd }}$ trimesters for estimation of Cortisol, ACTH, AFP and PAPP-A using ELISA method.

Results: The result showed that the mean systolic and diastolic blood pressures ( $\mathrm{mmHg}$ ) of HIV pregnant women were significantly higher than control ( $p<0.05$ respectively). The mean value of cortisol $(\mathrm{ng} / \mathrm{ml})$ in HIV pregnant women was significantly higher when compared with control subjects $(p<0.05)$. Cortisol showed inverse significant correlation with AFP in HIV-infected pregnant women. Maternal outcomes showed thatt HIV-infected pregnant women had significantly higher incidence of miscarriages and preeclampsia with higher incidence of perinatal outcomes such as low birth weight babies (LBW), preterm delivery, spontaneous abortion, still birth and low Apgar scores when compared with apparently normal pregnant women ( $P<0.05$ respectively).

Conclusion: the significantly higher cortisol level and BP in HIV pregnant women is indicative of oxidative stress due to perceived stress by HIV infection which might predispose the affected women to hypertension and preeclampsia. The highest adverse reactions observed in HIV pregnant women might be related to the damaged immune system by HIV infection however, the placental defect associated with increased placental permeability to AFP and the activity of the insulin-like growth factor (IGF) system is not related to the activity of stress thereby do not influence their birth outcomes.

Keywords: HIV; Stress Hormones; Pregnancy outcomes; Maternal serum markers

\section{Introduction}

HIV infection has remained a major public health challenge in subSaharan Africa, accounting for over two third of the global estimate of persons living with HIV/AIDS [1,2]. Young adults especially women within the reproductive age group and children are mainly affected. In most sub Saharan African countries including Nigeria, HIV infection has become a leading medical complication of pregnancy and cause of maternal and neonatal morbidity and mortality [1].

Stress is a normal physical response to events that makes body feel threatened. Stress response is the way of protecting the body by nervous system responds releasing a flood of stress hormones; including adrenaline and cortisol and it has been reported that HIV patients are under oxidative stress [3-5]. The continued increase in secretion of CRH, $\mathrm{ACTH}$, cortisol, and cytokines stimulate prostaglandin secretion which is responsible for the contraction and dilation of the smooth muscle, which could lead to preterm labor and premature rupture of membrane. Therefore, changes in the hormonal milieu due to stress may contribute to premature initiation of labor and preterm birth and other adverse pregnancy outcomes [6-9].
Prevention of viable spontaneous preterm birth and subsequently adverse pregnancy outcomes through screening is one of the key aims of antenatal care as these have implications for child, mother, and society [10]. If women can be identified to be at high risk in early pregnancy, they can be targeted for more intensive antenatal surveillance and prophylactic interventions (primary prevention). Clinically, it would be useful to be able to predict who will deliver preterm and or

*Corresponding author: Nkiruka Rose Ukibe, Department of Medical Laboratory Science, College of Health Sciences, Nnamdi Azikiwe University, Nnewi Campus, Anambra State, Nigeria, Tel: +2348062915510; E-mail: nr.ukibe@unizik.edu.ng/ ezinne4real2007@yahoo.com

Received September 15, 2017; Accepted September 27, 2017; Published October 06, 2017

Citation: Ukibe NR, Onyenekwe CC, Anojulu AA, Ukibe SN, Ikechukwu EC, et al. (2017) Possible Changes in Maternal Plasma Cortisol, Adrenocorticotropic Hormones, Pregnancy Associated Plasma Protein-A and Alpha-fetoprotein in HIV Pregnant Women at NAUTH Nnewi, Nigeria. J Bioanal Biomed 9: 250-255. doi:10.4172/1948-593X.1000188

Copyright: $\odot 2017$ Ukibe NR, et al. This is an open-access article distributed under the terms of the Creative Commons Attribution License, which permits unrestricted use, distribution, and reproduction in any medium, provided the original author and source are credited. 
Citation: Ukibe NR, Onyenekwe CC, Anojulu AA, Ukibe SN, Ikechukwu EC, et al. (2017) Possible Changes in Maternal Plasma Cortisol, Adrenocorticotropic Hormones, Pregnancy Associated Plasma Protein-A and Alpha-fetoprotein in HIV Pregnant Women at NAUTH Nnewi, Nigeria. J Bioanal Biomed 9: 250-255. doi:10.4172/1948-593X.1000188

have pregnancy complications. The predictors may be used in the management of women at high risk such as women with previous preterm labour, malaria, hypertension, diabetics, HIV, which also can be used as a part of a management protocol to individualize patient care [10]. Several markers more directly related to adverse obstetrics outcome have recently been proposed, some of which relate to direct causes of preterm labour, intrauterine growth restriction, preeclampsia and still birth such as cervical ultrasound measurement, fetal fibronectin (FFN), salivary estriol, serum CRH, PAPP-A and alphafeto-protein [11].

PAPP-A and Alpha fetoprotein are maternal $1^{\text {st }}$ and $2^{\text {nd }}$ trimester screening markers for congenital abnormality but in the absence of aforementioned, PAPP-A and Alpha fetoprotein can be used to access pregnancy at risk of adverse outcomes. Some authors found that in overall, there was no statistically significant difference between serum AFP and PAPP-A levels in HIV-positive women compared with HIVnegative women [11]. The underlying pathophysiologic mechanism for how HIV infection interacts with maternal serum analyte levels is not known [11]. The question of whether it is the infection itself or the stress perceived from the infection that is causing the effect, if any effect exists, is still unanswered. That is why the present study wants to assess the relationship of cortisol, ACTH concentration in HIV with PAPP-A, AFP, and adverse outcomes.

\section{Methods}

\section{Subjects}

Total size of 80 (eighty) subjects were conveniently recruited and divided into $40 \mathrm{HIV}$ positive pregnant women and 40 apparently healthy pregnant women who were not diagnosed of any disease condition as time of sample collection which serves as the control.

\section{Data collection methods}

Records of the physical measurements which includes the body weight and height of the pregnant women during their $1^{\text {st }}$ booking was obtained from maternal health records file. BMI was calculated as weight (in kilograms) divided by the square of height (in meters). Also the blood pressures at the two points of sample collections were obtained too from their records.

\section{Sample collection}

Initial $5 \mathrm{ml}$ of blood was collected from each subject in their $1^{\text {st }}$ trimester by venopuncture technique from the cubital fossa into labeled plain test tubes. The samples were allowed to clot and centrifuged at $5000 \mathrm{rpm}$ for $5 \mathrm{~min}$. The sera were transferred into properly labeled plain containers to be stored at -4 degree centigrade for the analysis of cortisol, ACTH and PAPP-A. Then, another $5 \mathrm{ml}$ was also collected from each subject when the same subjects entered their $2^{\text {nd }}$ trimester for the analysis of Alpha feto-protein.

\section{Inclusion criteria}

HIV infected pregnant women aged between 18-49 years were recruited for the study. Aged matched HIV uninfected pregnant women were also recruited.

\section{Exclusion criteria}

Pregnant women with multiple pregnancies, hepatitis B or C confections, malaria parasite infection, Tuberculosis, those that are diabetic, hypertensive, or have other chronic systemic infection and pregnant women within their $3^{\text {rd }}$ trimester were excluded from the study.

\section{Study site}

The study was carried out at antennal clinic of Prevention of mother- to- child transmission of HIV clinic unit of Nnamdi Azikiwe University Teaching Hospital, Nnewi, Anambra State, Nigeria. The analysis of Cortisol, ACTH, AFP and PAPP-A hormones was done using ELISA method at department of Chemical Pathology (NAUTH), Nnewi, Nigeria.

\section{Demographic and anthropometric variables}

The maternal variables assessed were; age, BMI, blood pressure, gestation age at delivery, mode of delivery, premature delivery at less than 37 weeks of gestation and maternal complications. The neonatal outcomes included birth weight, gestational age at birth and rate of APGAR scores less than 7 at one and five min (Table 1).

\section{Statistical analysis}

The version 20 of Statistical Package for Social Sciences (SPSS) was used in statistical analysis. The results were expressed as mean $( \pm$ $\mathrm{SD})$ and percentages. Comparisons were made using Student's t-test, ANOVA and chi square. Pearson correlation analysis was used to establish possible correlation between cortisol, AFP and PAPP-A and also between AFP and PAPP-A on birth outcomes. The P-value less than 0.05 were taken as significant.

\section{Results}

Age and anthropometric measurements of HIV positive pregnant and control women

The result shows that the mean \pm SD systolic and diastolic blood pressure $(\mathrm{mmHg})$ in HIV positive pregnant women $(124.5 \pm 8.6,70.0$ \pm 8.6) were significantly higher than the control $(104.0 \pm 7.6,63.4 \pm$ 6.2) $(\mathrm{p}<0.05$ respectively). On the other hand, the mean \pm SD BMI (kg/ $\left.\mathrm{m}^{2}\right)$ in HIV positive pregnant $(24.5 \pm 3.2)$ was significantly lower than control subjects $(26.8 \pm 3.8)(\mathrm{P}<0.05)$. However, there was no significant difference observed in the mean ages in both group ( $\mathrm{p}>0.05)$.

Levels of cortisol (ng/ml), ACTH (), AFP (MoM) and PAPP-A (MoM) in HIV-infected pregnant women and control subjects

The result showed that the mean serum cortisol $(\mathrm{ng} / \mathrm{ml})$ concentration in HIV positive pregnant women $(109.00 \pm 44.00)$ was significantly higher when compared to control subjects $(86.70 \pm 3.30)$ $(\mathrm{p}<0.05)$. However, there was no significant difference in the mean levels of ACTH, AFP and PAPP-A between HIV pregnant women (4.30 $\pm 1.50,1.30 \pm 0.10,0.70 \pm 0.20)$ and control subjects $(5.90 \pm 0.10,1.50 \pm$ $0.70,1.50 \pm 0.90)(\mathrm{P}>0.05$ respectively) (Table 2$)$.

Correlation of Cortisol (ng/ml), AFP (MoM) and PAPP-A (MoM) in HIV-infected pregnant women and control subjects

After controlling for age and BMI, Pearson's correlation analysis indicated lack of significant associations between cortisol and AFP, Cortisol and PAPP-A, ACTH and AFP and ACTH and PAPP-A respectively $(\mathrm{P}>0.05)$ (Table 3$)$.

\begin{tabular}{|c|c|c|c|}
\hline Characteristics & $\begin{array}{c}\text { HIV-infected Pregnant } \\
\text { women N=(35) }\end{array}$ & $\begin{array}{c}\text { Apparently healthy } \\
\text { pregnant women } \mathbf{N = ( 4 0 )}\end{array}$ & P-value \\
\hline Age (years) & $28.7 \pm 5.8$ & $28.6 \pm 4.5$ & 0.531 \\
\hline SBP $(\mathrm{mmHG})$ & $124.5 \pm 8.6$ & $104.0 \pm 7.6$ & 0 \\
\hline $\mathrm{DBP}(\mathrm{mmHG})$ & $70.0 \pm 8.6$ & $63.4 \pm 6.2$ & 0.034 \\
\hline $\mathrm{BMI}\left(\mathrm{kg} / \mathrm{m}^{2}\right)$ & $24.5 \pm 3.2$ & $26.8 \pm 3.8$ & 0.002 \\
\hline
\end{tabular}

Table 1: Demographic and anthropometric measurements of the study population. 
Citation: Ukibe NR, Onyenekwe CC, Anojulu AA, Ukibe SN, Ikechukwu EC, et al. (2017) Possible Changes in Maternal Plasma Cortisol, Adrenocorticotropic Hormones, Pregnancy Associated Plasma Protein-A and Alpha-fetoprotein in HIV Pregnant Women at NAUTH Nnewi, Nigeria. J Bioanal Biomed 9: 250-255. doi:10.4172/1948-593X.1000188

\begin{tabular}{|c|c|c|c|}
\hline Characteristics & $\begin{array}{c}\text { HIV-infected pregnant } \\
\text { women } \mathbf{N = ( 4 0 )}\end{array}$ & $\begin{array}{c}\text { Apparently healthy } \\
\text { pregnant women } \mathbf{N = ( 4 0 )}\end{array}$ & P-value \\
\hline Cortisol (ng/ml) & $109.00 \pm 44.00$ & $86.70 \pm 3.30$ & 0.046 \\
\hline ACTH (ng/ml) & $4.30 \pm 1.50$ & $5.90 \pm 0.10$ & 0.475 \\
\hline AFP (MoM) & $1.30 \pm 0.10$ & $1.50 \pm 0.70$ & 0.148 \\
\hline PAPP-A (MoM) & $0.70 \pm 0.20$ & $1.30 \pm 0.90$ & 0.271 \\
\hline
\end{tabular}

Table 2: Mean \pm (S.D) Cortisol, ACTH, AFP and PAPP-A in HIV-infected pregnant and control subjects.

\begin{tabular}{|c|c|c|}
\hline Variables & Correlation coefficient (r) & P-value \\
\hline Cortisol vs. AFP & -0.452 & 0.045 \\
\hline Cortisol vs. PAPP-A & -0.191 & 0.419 \\
\hline ACTH vs. AFP & 0.021 & 0.93 \\
\hline ACTH vs. PAPP-A & 0.227 & 0.335 \\
\hline
\end{tabular}

Table 3: Correlations of cortisol, ACTH with AFP and PAPP-A in HIV-infected pregnant women.

\section{Maternal outcomes in HIV infected pregnant women and control subjects.}

The result shows that HIV infected pregnant women experienced significantly higher number of miscarriages and preeclampsia when compared with the normal control pregnant women $(\mathrm{P}<0.05$ respectvely).

\section{Perinatal outcomes in HIV infected pregnant women and normal pregnant women.}

The results shows that $21(60 \%)$ HIV infected pregnant women out of 35 pregnant women had significantly higher numbers of Low birth weight babies when compared with $14(40 \%)$ observed in normal pregnant women $(\mathrm{P}<0.05), 21(72.4 \%) \mathrm{HIV}$ infected pregnant women out of 29 pregnant women had significantly higher incidence of preterm babies compared with only $8(27.6 \%)$ observed in normal pregnant women $(\mathrm{P}<0.05), 12(66.7 \%) \mathrm{HIV}$ infected pregnant women had significantly higher incidence of still birth when compared with 6 $(33.3 \%)$ observed in normal pregnant women $(\mathrm{P}<0.05) .15$ (60\%) HIV infected pregnant women out of 25 had significantly higher incidence of spontaneous abortion when compare with 10 (40\%) observed in control subjects $(\mathrm{P}<0.05)$. The Apgar score of less than seven at first min and fifth min respectively were significantly higher in HIV infected pregnant women $(27,25)(54.4 \%, 45.6 \%)$ when compared with apparently healthy pregnant women $(20,20)(56.8 \%, 43.2 \%)(\mathrm{P}<0.05$ respectively).

\section{Correlation of AFP (MoM), APP-A (MoM) with birth weight and Apgar scores in HIV infected pregnant women and control groups}

Pearson's correlation analysis indicate lack of significant associations between PAPP-A and Birth weight; PAPP-A and APGAR score at one min and at five min; AFP and birth weight; AFP and APGAR score and one min and five mins respectively ( $\mathrm{p}>0.05)$.

\section{Discussion}

From the results obtained in our study, it was observed that the body mass index of HIV pregnant women was significantly lower than apparently healthy individual. This is in contrast with some previous studies $[12,13]$. The authors observed changes in the nutritional profile of individuals with HIV since the introduction of HAART, with an increasing prevalence of obesity and a decrease in thinness. Other studies also have shown that the BMI of people living with HIV/AIDS do not differ from those of the general population [14-
16]. The difference in the study might be that some of HIV-infected pregnant women might be under stress compounded by their poor nutritional and socioeconomic status. Body mass index (BMI) is an anthropometric measurement for defining body composition and nutritional status. Initially, the BMI was used as a measure of obesity in developed countries, but it is now applied to define underweight and overweight adults in countries throughout the world [17]. In developed countries, poor nutritional status of women as defined by a low BMI has a negative effect on pregnancy outcomes, particularly low infant birth weight and preterm delivery $[18,19]$.

Furthermore, it was observed that the blood pressure of HIVinfected pregnant women was significantly higher than control pregnant women. This suggests that HIV- infected pregnant women might have tendency to develop hypertension and possibly preeclampsia. This was in line with the works of Gazzaruso et al. [20] and Coloma et al. [21]. The authors reported higher prevalence of hypertension in HIVinfected than in the HIV-uninfected population. The increasing blood pressure could be related to HIV-specific factors such as lipodystrophy [20,22-24] and higher $\mathrm{CD}^{4}$ cell count [20,25]. Additionally, Initiation of ART has been associated with development of hypertension and/or elevation of $\mathrm{BP}$ within the normal range in several studies [10,26-28].

The present study also showed that HIV-infected pregnant women have significantly higher plasma cortisol level when compared to normal pregnant women. HIV has been described as one of the leading disease associated endocrine disruptors and stressor [29]. Therefore, the significant increase in serum cortisol observed in our study in the HIVinfected pregnant women relative to normal pregnant women indicates that HIV is a stressor and possible endocrine disruptor. Our finding is consistent with the report of Miotti et al. [30] which demonstrated that HIV-infected women are at greater risk of increased cortisol secretion during pregnancy than uninfected women. This could be coming from the fact that HIV-infected pregnant women have to deal with specific psychosocial issues related to pregnancy or to the child, such as maternal guilt, fear of infecting the fetus, stigma, insufficient social network, stress, poverty, and interpersonal issues emerging around diagnostic disclosure leading to depression too. It is now known that in depression there is over activity of the hypothalamicpituitary-adrenal axis, which leads to increased secretion of cortisol [31]. Acute or chronic psychosocial experiences [32] and the biologic measure of serum or salivary cortisol concentrations [33] have been associated with shortened duration of gestation and intrauterine growth restriction. Cortisol is a regulatory hormone involved in the hypothalamic-pituitary-adrenal axis (HPA) response to stress as well as in the fetal-placental-maternal neuroendocrine system regulating the maintenance of pregnancy and the timing of parturition [34]. Cortisol and corticotropin-releasing hormone (CRH) concentrations rise exponentially over the course of pregnancy due to a positive feedback mechanism via the placenta [35]. They peak at the time of delivery and have been hypothesized to serve in regulating the 'placental clock', determining the timing of parturition [36]. CRH promotes fetal prostaglandin and estrogen synthesis, which lead to myometrial activation and contractility [35]. Cortisol also is involved in fetal growth and maturation. The late gestation rise in cortisol concentration is related to a shift from rapid fetal growth towards tissue maturation [37]. Elevated cortisol concentration is negatively associated with IGF1 activity [38] and, importantly, is involved in fetal lung maturation through the production of surfactant to prepare the fetus for postnatal life [39].

The elevated cortisol levels may also be due to stress-related shift of steroid production from adrenal androgens towards cortisol or 
the increase in the concentration of cortisol-binding globulin (CBG) observed with the HIV disease progression [31]. Direct infection of the adrenal gland by HIV has been reported to impair the function of the gland. Many of the drugs used in the treatment of HIV can also interfere with adrenal function [31]. Cortisol response to stressors is generally blunted during pregnancy [40] Despite the physiologic explanations for a normal rise in cortisol during pregnancy, higher than expected increases in cortisol and CRH concentrations have important short- and long-term negative functional consequences on the health of the pregnancy and the offspring in later life [41,42]. In the short term, elevated $\mathrm{CRH}$ is associated with placental dysfunction, including shallow trophoblast invasion and poor placental vascularization which can lead to intrauterine growth restriction and preeclampsia [43]. Elevations in perceived stress and cortisol concentrations have been related to higher concentrations of pro-inflammatory cytokines and lower concentrations of anti-inflammatory cytokines [44,45]. In the longer-term, excess glucocorticoid exposure has been associated with the life-long function of the HPA axis in the offspring, and has been hypothesized to increase susceptibility to a variety of conditions including depression, hypertension, type 2 diabetes mellitus, and cognitive impairments $[42,46]$. The fetus is somewhat buffered from the effects of high maternal cortisol concentrations through the activity of the 11- $\beta$-hydroxysteroid dehydrogenase (HSD)-2 enzyme in the placenta, which converts maternal cortisol to an inactive cortisone [47]. Yet this is not a perfect barrier and fetal and maternal cortisol concentrations are highly correlated suggesting that abnormally high maternal cortisol concentrations could affect the developing fetus [48]. HAART has also been reported to increase cortisol level [49] and also increase chemically reactive species in human [50]. These reactive species probably increase the oxidative stress in the subjects, who are already under oxidative stress due to HIV infection. This state of increased oxidative stress causes a marked increase in the level of cortisol. Additionally, The HPA axis is activated during infection and cortisol has important immunomodulatory effects [51], so elevated cortisol concentration may have been more strongly associated with an infectious disease burden rather than malnutrition.

Association of stress hormones and fetal viability hormones has not been extensively studied. In the present study, cortisol showed significant negative correlation with AFP in HIV-infected pregnant women. This means that as cortisol levels increases, invariably, AFP concentration reduces. This implies that any adverse pregnancy outcomes found among HIV-infected pregnant women in this present study would not be associated with AFP because low maternal AFP was not associated with any adverse pregnancy outcome [52]. This agrees with the study done by [53], where cortisol and $\alpha$-fetoprotein (AFP) levels were measured in amniotic fluid (AF) samples at 15-20 weeks of gestation from 125 normal pregnancies and 29 pregnancies affected by aneuploidy and significant inverse linear correlation was found between cortisol and AFP [53].

In the maternal outcomes, it was observed that HIV-infected pregnant women had significantly higher incidence of miscarriages and preeclampsia.

The role of HIV infection in the development of preeclampsia is controversial. Wimalasundera et al. [54] found a lower rate of PE among untreated HIV-infected women when compared to uninfected women or HIV-infected on treatment. Several studies show no difference in the rates of PE between HIV-uninfected and HIV-infected women treated with HAART $[55,56]$ or even a lower rate of PE among HIVinfected treated when compared to uninfected women [57]. The use of
HAART at conception was a risk factor for PE/E. This is in agreement with two other studies which showed that the use of HAART prior to pregnancy increase the odds for hypertension and PE [58,59]. In the present study, there was no stratification with use of HAART in relation to conception and this could explain the discrepancy among studies. Some authors suggest that immune restoration, secondary to the use of HAART could be involved in the development of PE [54]. It has also been shown that low levels of retinol are correlated with PE and it was suggested that a mechanisms of HAART-induced PE could be a reduction of serum retinol concentrations due to hepatotoxicity $[60,61]$. HIV-infected pregnant women using HAART present a shift towards a $\mathrm{Th}_{1}$ cytokine production while, in a healthy pregnancy, a $\mathrm{Th}_{2}$ response is predominantly observed [62,63]. Also a $\mathrm{Th}_{1}$ immune response is observed in PE [64]. It is possible that HIV-infected pregnant women on HAART, especially those with long exposure to therapy, would have a blunted shift of $\mathrm{Th}_{2}$ cytokines increasing the predisposition to eclampsia [64].

In perinatal outcomes in this study, HIV-infected pregnant women had significantly higher incidence of low birth weight babies (LBW), preterm babies, still birth, spontaneous abortion and low Apgar scores when compared to the normal pregnant women. The HIV associated LBW might be related to the damaged human immune system, especially the reduced $\mathrm{CD}^{4+} \mathrm{T}$ cells and immunosuppression. Some studies have reported that HIV-1 can replicate in the placenta $[43,65]$ and it has also been shown that HIV-1 infection may alter the cytokine profile in the placenta [66,67]. This may affect the function of placenta during pregnancy, and then restrict the development of fetus, which might be another incentive of low birth weight. It has been previously reported that compared with unexposed children, children who encountered intrauterine HIV exposure are more vulnerable to stunting, underweight and wasting, and their birth weight, height and head circumference are generally lower than their unexposed counterparts [68].

The impact of HIV-1 infection on spontaneous abortion is still controversial, and most studies on obstetrical outcome in women with HIV infection have only addressed the effect on liveborn children, with very few addressing the effect on spontaneous abortion. Nonetheless, several hypotheses have been developed. There may be a direct effect of HIV on the placenta and/or on embriogenesis: HIV has been identified in fetuses during the first weeks of pregnancy, suggesting that it can be transmitted across the placenta early in gestation $[69,70]$. The presence of HIV-infected monocyte/macrophages in the endometrial mucosa has also been demonstrated [71]. There may also be thymic abnormalities: the effect of thymic injury found in fetal HIV-infected material [72] with altered cytokine production may result in an adverse uterine, endometrial, or decidual (or a combination) environment for the continuation of pregnancy or in some as-yet-unrecognized fetal effect leading to fetal demise. Finally, the cumulative immunosuppressive effect of HIV- infection and pregnancy may facilitate ascending infection, causing bacterial or viral infection of the villi $[72,73]$.

Intriguingly, babies of treated HIV-infected women in our study were found to be at an increased risk of very low Apgar scores just after birth. APGAR score is a quick test performed on a baby at 1 and 5 mins after birth. The 1-min score determines how well the baby tolerated the birthing process. The 5-min score tells the doctor how well the baby is doing outside the mother's womb. A low APGAR score usually indicates a poorer overall prognosis. The APGAR scores of the HIVexposed infants might have been influenced by the associated clinical conditions of the pregnant mothers, as demonstrated in the study 
Citation: Ukibe NR, Onyenekwe CC, Anojulu AA, Ukibe SN, Ikechukwu EC, et al. (2017) Possible Changes in Maternal Plasma Cortisol, Adrenocorticotropic Hormones, Pregnancy Associated Plasma Protein-A and Alpha-fetoprotein in HIV Pregnant Women at NAUTH Nnewi, Nigeria. J Bioanal Biomed 9: 250-255. doi:10.4172/1948-593X.1000188

performed by [74] who found that HIV-infected women were at higher risk of experiencing an adverse pregnancy outcome, such as a low APGAR score and perinatal mortality or Alternatively, HIV treatment may have prevented deaths in these babies who instead are born with low Apgar scores [74].

There was no significant correlation between the alpha feto-proteins and pregnancy associated plasma protein-A with birth weight and Apgar scores in the HIV-infected pregnant women. This shows that the pregnancy outcomes of the HIV-infected pregnancy was not influenced by the concentration of AFP and PAPP-A.

\section{Conclusion}

The significantly higher cortisol level and BP in HIV pregnant women is indicative of oxidative stress due to perceived stress by HIV infection which might predispose the women to hypertension and preeclampsia. The highest adverse reactions observed in HIV pregnant women might be related to the damaged immune system by HIV infection however, the placental defect associated with increased placental permeability to AFP and the activity of the insulin-like growth factor (IGF) system is not related to the activity of stress thereby do not influence their birth outcomes.

\section{Acknowedgements}

We are immensely grateful to all the HIV infected pregnant mothers at antennal clinic of Prevention of mother- to- child transmission of HIV clinic unit of Nnamdi Azikiwe University Teaching Hospital, Nnewi, Anambra State, Nigeria for given us their informed consent to use their sample for analysis.

\section{Authors' Contributions}

$\mathrm{NRU}, \mathrm{CCO}$ and AAA participated in the project design, data analysis and manuscript. SNU, INM and UAE performed major experiments. All authors read and approved the final manuscript.

\section{Ethics Approval and Consent to Participate}

All authors hereby declare that all experiment and procedure have been examined and approved by the appropriate board of ethics committee of Nnamdi Azikiwe University Teaching Hospital Nnewi, South East Nigeria, and research have therefore been performed in accordance with the standards laid down in the 1964 Declaration of Helsinki.

\section{References}

1. Gregson S, Garnett GP, Anderson RM (1994) Is HIV-1 likely to become a leading cause of adult mortality in sub-Saharan Africa? J Acqire Immune Def Synd 7: 839-852.

2. UNAIDS (1998) AIDS epidemic update: December 1998. Geneva, Joint United Nations Programme on HIVIAIDS.

3. Martin-Ruiz R, Puig MV, Celada P, Shapiro DA, Roth BL, et al. (2001) Control of serotonergic function in medial prefrontal cortex by serotonin-2A receptors through a glutamate-dependent mechanism. J Neuroscience 21: 9856-9866.

4. Diego MA, Jones NA, Field T, Hernandez-Reif $M$, Schanberg $S$, et al. (2006) Maternal psychological distress, prenatal cortisol and fetal weight. Psychosomatic Med 68: 747-753.

5. Gurguis GN, Meador-Woodruff JH, Haskett RF, Greden JF (2009) Multiplicity of depressive episodes: Phenomenological and neuroendocrine correlates. Bio Psychiatry 27: 1156-1164

6. Dole N1, Savitz DA, Hertz-Picciotto I, Siega-Riz AM, McMahon MJ, et al. (2003) Maternal stress and preterm birth. Am J Epidemiol 157: 14-24.

7. Khasan AS, McNamee R, Abel KM, Pedersen MG, Webb RT, et al. (2008) Reduced Infant Birth Weight Consequent upon Maternal Exposure to Severe Life Events. Psychosomatic Med 70: 688-694.

8. Latendresse, G (2009) The Interaction between Chronic Stress and Pregnancy: Preterm Birth from a Biobehavioral Perspective. J Midwifery Women's Health 54: 8-17.
9. Class $Q A$, Lichtenstein $P$, Långström N, D'Onofrio BM (2011) Timing of Prenatal Maternal Exposure to Severe Life Events and Adverse Pregnancy Outcomes: A Population Study of 2.6 Million Pregnancies. Psychosomatic Med 73: 234-241.

10. Crane HM, Van Rompaey SE, Kitahata MM (2006) Antiretroviral medications associated with elevated blood pressure among patients receiving highly active antiretroviral therapy. AIDS 20: 1019-1026.

11. Goffinet $F$ (2005) Epidemiological research unit on women and children's health. Br J Obstet Gyne 112: 38-47.

12. Jaime PC, Florindo AA, Latorre MRDO, Brasil BG, Santos ECM, et al. (2004) Prevalence of overweight and central obesity in HIVIAIDS patients treated with highly active antiretroviral therapy. Rev on Brazilian Epidemiol 7: 065-072.

13. Hendricks KM, Mwamburi DM, Newby PK, Wanke CA (2008) Dietary patterns and health and nutrition outcomes in men living with HIV infection. Am J Clin Nutr 88: 1584-1592.

14. Ford ES, Mokdad AH (2008) Epidemiology of obesity in the Western Hemisphere. Atlanta: Centers for Disease Control and Prevention from 1984 to 2003. AIDS 19: 953-960

15. Leite LHM, Sampaio ABMM (2008) Metabolic abnormalities and overweight in HIVIAIDS persons treated with antiretroviral therapy. Rev Nutr 21: 277-283.

16. Oliveira OMV, Medeiros RS, Nascimento MAB, Boni MS (2008) Nutritional profile and risk factors for central obesity in people living with HIV / AIDS. Comun Ciênc Saúde. 19: 305-314.

17. World Health Organization (2000) Obesity: preventing and managing the global epidemic: report of a WHO consultation. WHO Press; Geneva: WHO Technical Report Series 894.

18. Neggers Y, Goldenberg RL (2003) Some thoughts on body mass index micronutrient intakes and pregnancy outcome. J Nutr 133: 1737S-1740S.

19. Helgstrand S, Andersen AM (2005) Maternal underweight and the risk of spontaneous abortion. Acta Obstet Gynecol Scand 84: 1197-1201.

20. Gazzaruso C, Bruno R, Garzaniti A (2003) Hypertension among HIV patients: lipodystrophy. AIDS 15: 2001-2010.

21. Coloma Conde AG, Alvarez AM, Roca-Cusachs CA, Domingo PP, Puig CM (2008) Prevalence of arterial hypertension and lipid profile in HIV patients. Medicina Clinica 131: 681-684.

22. Sattler FR, Qian D, Louie S (2001) Elevated blood pressure in subjects with therapy on blood pressure in HIV-infected patients. A prospective study in a cohort of naive patients. HIV Med 7: 010-015.

23. Jerico C, Knobel H, Montero M (2005) Hypertension in HIV-infected antiretroviral therapy and hypertension in a large cohort of men followed prevalence and relationships to insulin resistance and metabolic syndrome. J Hypertens 21: 1377-1382.

24. Crane HM, Grunfeld C, Harrington RD, Kitahata MM (2009) Lipoatrophy and lipohypertrophy are independently associated with hypertension. HIV Med 10: 496-503.

25. Goulet JL, Fultz SL, Rimland D (2007) Aging and infectious diseases: AIDS 16: $1965-1968$.

26. Chow DC, Souza SA, Chen R, Richmond-Crum SM, Grandinetti A, et al. (2003) Elevated blood pressure in HIV-infected individuals receiving highly active antiretroviral therapy. HIV Clin Trial 4: 411-416.

27. Seaberg EC, Munoz A, Lu M (2005) Association between highly active patients: prevalence and related factors. Am J Hypertens 18: 1396-1401.Goulet JL, Fultz SL, Rimland D, Butt A, Gibert C, et al. (2007) Aging and

28. infectious diseases: do patterns of comorbidity vary by HIV status, age, and HIV severity? Clin Infect Dis 45: 1593-1601.

29. Grinspoon S, Corcoran C, Anderson E, Hubbard J, Stanley T, et al. (1999) Sustained anabolic effects of long-term androgen administration in men with AIDS wasting. Clin Infect Dis 28: 634-636.

30. Miotti PG, Liomba G, Dallabetta GA, Hoover DR, Chiphangwi JD, et al (1997) T lymphocyte subsets during and after pregnancy: analysis in human immunodeficiency virus type 1 -infected and -uninfected Malawian mothers. J Infect Dis 165: 1116-1119.

31. Ebuehi OA, Awolola A, Akanmu AS (2015) Changes in Serum Cortisol, Thyroid Hormones and Lipid Profiles in Nigerian Men and Women on 1st and 2nd Line Antiretroviral Therapy for 52 Weeks. Inter J Virolo Mole Bio 4: 12-18. 
Citation: Ukibe NR, Onyenekwe CC, Anojulu AA, Ukibe SN, Ikechukwu EC, et al. (2017) Possible Changes in Maternal Plasma Cortisol, Adrenocorticotropic Hormones, Pregnancy Associated Plasma Protein-A and Alpha-fetoprotein in HIV Pregnant Women at NAUTH Nnewi, Nigeria. J Bioanal Biomed 9: 250-255. doi:10.4172/1948-593X.1000188

32. Shapiro GD, Fraser WD, Frasch MG, Séguin JR (2013) Psychosocial stress in pregnancy and preterm birth: associations and mechanisms. J Perinat Med 41: $631-645$

33. Giurgescu C (2009) Are maternal cortisol levels related to preterm birth? J Obstet Gynecol Neonatal Nurs 38: 377-390.

34. Voltolini C, Petraglia F (2014) Neuroendocrinology of pregnancy and parturition. Handb Clin Neurol 124: 17-36.

35. Smith R, Paul J, Maiti K, Tolosa J, Madsen G (2012) Recent advances in understanding the endocrinology of human birth. Trends Endocrinol Metab 23 516-523.

36. Sandman CA, Glynn L, Schetter CD, Wadhwa P, Garite T, et al. (2006) Elevated maternal cortisol early in pregnancy predicts third trimester levels of placental corticotropin releasing hormone $(\mathrm{CRH})$ : priming the placental clock. Peptides 27: $1457-1463$

37. Fowden AL, Forhead AJ (2013) Endocrine interactions in the control of fetal growth. Nestle Nutr Inst Workshop Ser 74: 91-102.

38. Sferruzzi-Perri AN, Vaughan OR, Forhead AJ, Fowden AL (2013) Hormona and nutritional drivers of intrauterine growth. Curr Opin Clin Nutr Metab Care 16: $298-309$

39. Bolt RJ, van Weissenbruch MM, Lafeber HN, Delemarre-van de Waal HA (2001) Glucocorticoids and lung development in the fetus and preterm infant. Pediatr Pulmonol 32: 76-91

40. de Weerth C, Buitelaar JK (2005) Physiological stress reactivity in human pregnancy--a review. Neurosci Biobehav Rev 29: 295-312.

41. Christian P, Stewart CP (2010) Maternal Micronutrient Deficiency, Fetal Development, and the Risk of Chronic Disease. J Nutr 140: 437-445.

42. Moisiadis VG, Matthews SG (2014) Glucocorticoids and fetal programming part 1: Outcomes. Nat Rev Endocrinol 10: 391-402.

43. Kalantaridou SN, Zoumakis E, Makrigiannakis A, Lavasidis LG, Vrekoussis T, et al. (2010) Corticotropin-releasing hormone, stress and human reproduction: an update. J Reprod Immunol 85: 33-39.

44. Coussons-Read ME, Okun ML, Nettles CD (2007) Psychosocial stress increases inflammatory markers and alters cytokine production across pregnancy. Brain Behav Immun 21: 343-350.

45. Coussons-Read ME, Okun ML, Schmitt MP, Giese S (2005) Prenatal stress alters cytokine levels in a manner that may endanger human pregnancy. Psychosom Med 67: 625-631.

46. Davis EP, Sandman CA (2010) The timing of prenatal exposure to materna cortisol and psychosocial stress is associated with human infant cognitive development. Child Dev 81: 131-148.

47. Moisiadis VG, Matthews SG (2014) Glucocorticoids and fetal programming part 2: Mechanisms. Nat Rev Endocrinol 10: 403-411.

48. Gitau R, Cameron A, Fisk NM, Glover V (1998) Fetal exposure to materna cortisol. Lancet 352: 707-708.

49. Manolescu L, Marinescu P (2013) Sex differences in HIV-1 viral load and absolute CD4 cell count in long term survivors HIV-1 infected patients from Giurgiu, Romania. Revista Romana de Med Lab 21: 217-224.

50. Awodele O, Olayemi SO, Nwite JA, Adeyemo TA (2012) Investigation of the levels of oxidative stress parameters in HIV and HIV-TB co-infected patients. $J$ Infect Dev Ctries 6: 79-85.

51. Bellavance MA, Rivest S (2014) The HPA-Immune Axis and the Immunomodulatory Actions of Glucocorticoids in the Brain. Front Immunol 5: 136.

52. Burton BK (1988) Outcome of pregnancy in patients with unexplained elevated or low levels of maternal serum alpha-fetoprotein. Obstet Gynecol 72: 709-713.

53. Drugan A, Subramanian MG, Johnson MP, Evans MI (1988) Amniotic fluid cortisol and alpha-fetoprotein in normal and aneuploid pregnancies. Fetal The 3: 192-197.

54. Committee on Obstetric Practice (2001) ACOG committee opinion scheduled Cesarean delivery and the prevention of vertical transmission of HIV infection. Number 234, May 2000 (replaces number 219, August 1999). Int J Gynaecol Obstet 73: 279-281.

55. Wimalasundera RC, Larbalestier N, Smith JH, de Ruiter A, Thom SA, et al (2002) Pre-eclampsia, antiretroviral therapy and immune reconstitution. Lance 360: $1152-1154$
56. Conde-Agudelo A, Villar J, Lindheimer M (2008) Maternal infection and risk of preeclampsia: systematic review and metaanalysis. Am J Obstet Gynecol 198: $7-22$

57. Boyajian T, Shah PS, Murphy KE (2012) Risk of preeclampsia in HIV-positive pregnant women receiving HAART: a matched cohort study. J Obstet Gynaecol Can 34: 136-141.

58. Mattar R, Amed AM, Lindsey PC, Sass N, Daher S (2004) Preeclampsia and HIV infection. Eur J Obstet Gynecol Reprod Biol 117: 240-241.

59. Lambert JS, Watts DH, Mofenson L, Stiehm ER, Harris DR, et al. (2000) Risk factors for preterm birth, low birth weight, and intrauterine growth retardation in infants born to HIV-infected pregnant women receiving zidovudine. Pediatric AIDS Clinical Trials Group 188 Team. AIDS 14: 1389-1399.

60. Parekh N, Ribaudo H, Souda S, Chen J, Mmalane M, et al. (2011) Risk factors for very preterm delivery and delivery of very-small-for-gestational-age infants among HIV-exposed and HIV-unexposed infants in Botswana. Int J Gynaecol Obstet 115: 20-25

61. Zhang C, Williams MA Sanchez SE, King IB, Ware-Jauregui S, et al. (2001) Plasma concentrations of carotenoids, retinol, and tocopherols in preeclamptic and normotensive pregnant women. Am J Epidemiol 153: 572-580.

62. Mawson AR (2003) Effects of antiretroviral therapy on occurrence of preeclampsia. Lancet 361: 347-348.

63. Jonsson Y, Matthiesen L, Berg G, Emerudh J, Nieminen K, et al. (2005) Indications of an altered immune balance in pre-eclampsia: a decrease in in vitro secretion of IL-5 and IL-10 from blood mononuclear cells an in blood basophil counts compared with normal pregnancy. J Repro Immunol 66: 69-84.

64. Fiore S, Newell ML, Trabattoni D, Thorne C, Gray L, et al. (2006) Antiretrovira therapy-associated modulation of Th1 and Th2 immune responses in HIVinfected pregnant women. J Repro Immunol 70: 143-150.

65. Laresgoiti-Servitje E, Gómez-López N, Olson DM (2010) An immunological insight into the origins of pre-eclampsia. Hum Reprod Update 16: 510-524.

66. Kumar SB, Handelman SK, Voronkin I (2011) Different regions of HIV-1 subtype $\mathrm{C}$ envelope are associated with placental localization and in utero mother-tochild transmission. J Virol 85: 7142-7152.

67. Moussa M, Roques P, Fievet N (2001) Placental cytokine and chemokine production in HIV-1-infected women: trophoblast cells show a different pattern compared to cells from HIV-negative women. Clin Exper Immunol 125: 455-464.

68. Faye A, Pornprasert S, Mary JY (2007) Characterization of the main placenta cytokine profiles from HIV-1-infected pregnant women treated with antiretroviral drugs in France. Clin Exper Immunol 149: 430-439.

69. McGrath CJ, Nduati R, Richardson BA, Kristal AR, Mbori-Ngacha D, et al. (2012) The prevalence of stunting is high in HIV-1-exposed uninfected infants in Kenya. J Nutr 142: 757-763.

70. Sprecher S, Soumenkoff G, Puissant F, Degueldre M (1986) Vertical transmission of HIV in 15-week fetus. Lancet 328: 288-289.

71. Maury W, Potts BJ, Rabson AB (1989) HIV-1 infection of first trimester and term human placental tissue: a possible mode of maternal-fetal transmission. $\mathrm{J}$ Infect Dis 160: 583-588.

72. Peuchmaur M, Emilie D, Vazeux R, Pons JC, Delfraissy JF, et al. (1989) HIVassociated endometritis. AIDS 3: 239-241.

73. Langstone C, Lewis DE, Hammill HA (1995) Excess intrauterine fetal demise associated with maternal human immunodeficiency virus infection. J Infect Dis 172: $1451-1460$

74. Areechokchai D, Bowonwatanuwong C, Phonrat B, Pitisuttithum P, Maek A-Nantawat W (2009) Pregnancy outcomes among HIV-infected women undergoing antiretroviral therapy. AIDS J 3: 8-13. 